\title{
DIGITAL IMAGE CORRELATION TECHNIQUE AS A TOOL FOR KINEMATICS ASSESSMENT OF STRUCTURAL COMPONENTS
}

\author{
Adam BRODECKI*, Tadeusz SZYMCZAK*, Zbigniew KOWALEWSKI ${ }^{*}$
}

*Centre for Material Testing, Motor Transport Institute, ul. Jagiellońska 80, 03-301 Warszawa, Poland

*Department of Experimental Mechanics, Institute of Fundamental Technological Research, ul. Pawińskiego 5B, 02-106 Warszawa, Poland

adam.brodecki@its.waw.pl, tadeusz.szymczak@its.waw.pl, zkowalew@ippt.pan.pl

received 24 May 2017, revised 28 May 2018, accepted 30 May 2018

\begin{abstract}
The paper reports the results of tests carried out for kinematic properties determination of components under cyclic loading. DIC system called 5M PONTOS was employed to follow variations of displacement versus time. It was conducted by the use of markers stuck on selected sections of components tested. The results are presented in 2D and 3D coordinate systems expressing behaviour of such elements as: mechanical coupling device, boat frame and car engine. These data enabled to capture weak and strong sections of the component examined at various loading conditions.
\end{abstract}

Key words: Digital Image Correlation System, Cyclic Loading, PONTOS, Motion, Displacement, 3D Coordinate System

\section{INTRODUCTION}

Digital Image Correlation (DIC) method is the contactless technique, which has been developed in the last 15 years. Application of new mathematical algorithms and great progress in $C C D$ (Charge-Coupled Device) cameras quality have enabled designing the effective DIC systems. Equations for determination of solid bodies deformation have been employed to follow differences on a sprayed grey background having black dots stochastically arranged (Chu et al., 1985; Bornert et al., 2009; Long et al., 2012). On the basis of these data the components of displacement can be calculated directly, and subsequently, the full-field strain maps elaborated. As it is noticed by many research groups, this method can be applied for examination of various types of specimens such as: flat (Toussaint et al., 2008), tubular and hourglass (Kamaya and Kawakubo, 2011) and CT.

\section{SELECTED ACHIEVEMENTS IN DIC APPLICATION}

DIC technique can be used to measure strain distribution on flat specimen under biaxial stress state, even for unidirectional carbon fibre-reinforced epoxy composite $\left[+45^{\circ} / 0^{\circ} /-45^{\circ} / 90^{\circ}\right] 2 \mathrm{~s}$ (Gower and Shaw, 2006). As it was investigated by the authors the DIC results are similar to data from FEA (Finite Element Analysis) and strain gauge measurements, Fig. 1a.

DIC method enables to follow evaluation of the strain distribution close to various types of defects (natural and artificial) and capturing important features appearing before material fracture (Szymczak et al., 2016a, b). Young's modulus (E), yield point (YP) and ultimate tensile strength (UTS) can be determined by means of DIC method (Szymczak et al., 2016b). It was also confirmed later for a high-strength steel called the S700 MC, Fig. $1 \mathrm{~b}$.

DIC technique can be also used for determination of the kinematic properties of various elements. In this case, DIC uses markers stuck on selected zones of components tested, Fig. 2. They are in the form of white-black dots covered very often by reflected layer. Their arrangement is usually formulated on the basis of geometrical axes of the object examined.

a)

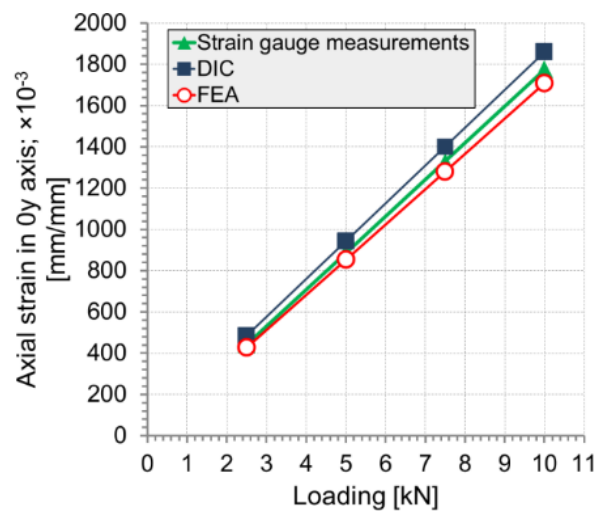

b)

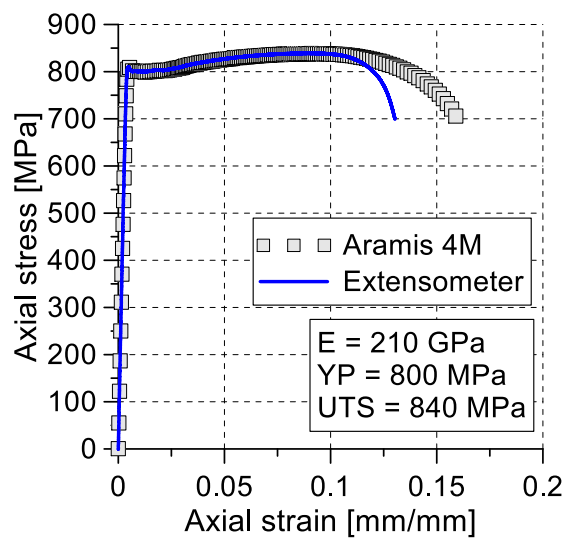

Fig. 1. Comparison of the results obtained using various measurement techniques: (a) strain gauge measurements, DIC and FEA (Gower and Shaw, 2006); (b) DIC and extensometer for the S700 MC steel 
Dimensions of markers (GOM) are within a range from $0.4 \mathrm{~mm}$ to $25 \mathrm{~mm}$. They can be calculated using geometrical features of DIC system and test details like a dimension of the measurement zone in the $0 x$ axis direction and a value of coefficient depending on the system applied: 0.0004 (4 and 5M PONTOS), 0.002 (12M PONTOS) and $0.4 \mathrm{~mm}$ (for high speed cameras). Typical DIC system contains two cameras (stereo device), working stations and calibration equipment (Fig. 3). a)

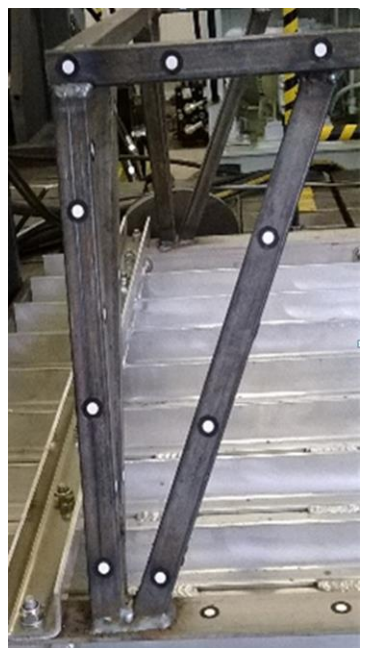

b)

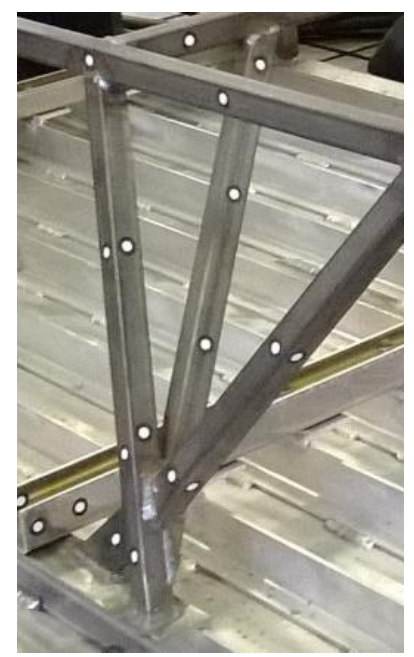

Fig. 2. Distribution of markers for measurements in: (a) 2D; and (b) 3D coordinate systems

a)

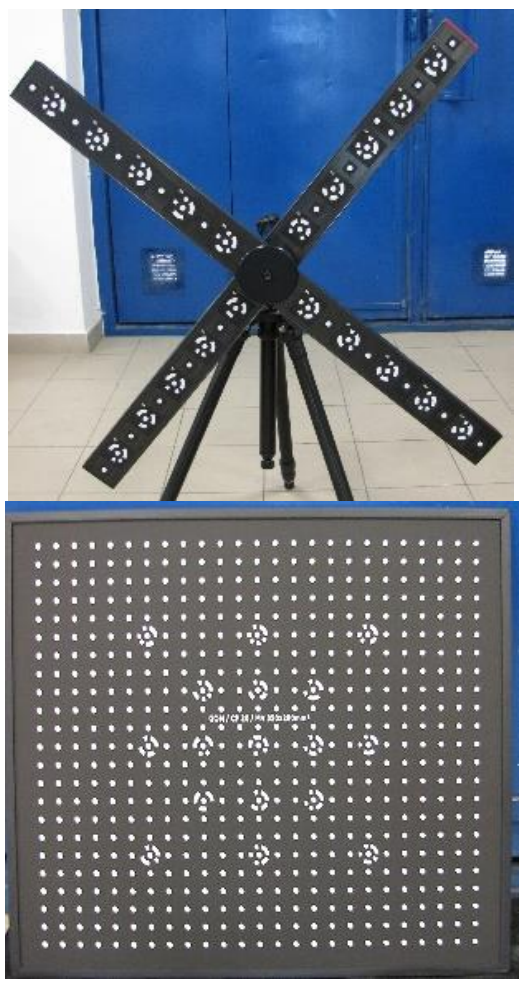

Fig. 3. The 5M PONTOS calibration devices: (a) cross; (b) plate

Application of the 5M PONTOS requires calibration stage, which should be directly conducted before the main test. This part of experimental procedure employs cross (Fig. $3 a$ ) or plate (Fig. 3b) having measurements dots located at various orientation in $3 \mathrm{D}$ coordinate system. The smallest sensor is called CQ 10×8 $[\mathrm{mm}]$ and enables observation of the measuring zone from $9 \times 7[\mathrm{~mm}]$ up to $12 \times 10[\mathrm{~mm}]$. The biggest one is signed as CC20 $2000 \times 1600[\mathrm{~mm}]$ and it is used for the measuring volume of $1600 / 1300[\mathrm{~mm}] \times 2300 / 1900[\mathrm{~mm}]$. These zones are followed by the use of $C C D$ camera chip at resolution of $2448 \times 2050$ pixels. Maximum sampling rate at typical configuration is equal to $15 \mathrm{~Hz}$ and $29 \mathrm{~Hz}$ with binning. The equipment is positioned in the centre of the measurement zone, and it is subjected to movements and rotations reflecting possible location of the object (www.gom.com).

In the case of 5M PONTOS two kinds of markers can be applied. Typically, when lightening conditions are acceptable, black dots on a white background can be used. In the opposite case the markers with a fluorescence layer are recommended. Their diameters can be equal to: $0.4 \mathrm{~mm}, 0.8 \mathrm{~mm}, 1.5 \mathrm{~mm}, 3 \mathrm{~mm}, 5 \mathrm{~mm}$, $8 \mathrm{~mm}, 12 \mathrm{~mm}, 18 \mathrm{~mm}$ and $25 \mathrm{~mm}$. They are selected applying multiplication of length of measuring volume and coefficient, which is equal to 0.004 for the 5M PONTOS (www.gom.com).

A number of data in the form displacement versus time is limited by the number of photos for recording. Therefore, all tests under cyclic loading should have clearly selected stages for displacement analysis.

The 5M PONTOS device was used to determine deformation and vibration of a large-volume tractor tyre during dynamic test (Brinkmann et al., 2007). Vertical mode shape on the top reversal point of the tyre was elaborated on the basis of directions and magnitude of displacement determined for each measuring point.

An analysis of the airplane wing under cyclic loading is another external application of DIC system (Berger et al., 2010). Variations of displacement in $3 \mathrm{D}$ coordinate system versus frequency were presented and compared with data recorded using accelerometer. Differences between the results captured by both techniques were significant. They were within a range from $0 \%$ to $7.38 \%$ for seven measurement points taken into account. It has to be mentioned however, that for some other points it was much higher.

The DIC technique was also successfully applied for identification of a shape mode of the wind turbine blade (Bagersada et al., 2012). The results of the wind parameters analysis at the beginning and subsequent stages enabled identification of free vibration. Two modes of shape were extracted and compared with their form before excitation.

DIC was also used for capturing of kinematic parameters of the NASA vehicle conception called The Scarab (Creager et al., 2015). Tracking of each wheel was executed by means of the PONTOS system.

This work supplements in a certain way the previous knowledge regarding the research possibilities of DIC.

\section{EXPERIMENTAL PROCEDURE}

Testing procedure was designed to check suitability of the $5 \mathrm{M}$ PONTOS for detection of displacement components in 2D and 3D measurements of various structural elements such as: mechanical coupling device, car engine, and boat frame. Various types of loading were applied to enforce a movement of structural elements tested.

Symmetrical signal of cyclic force was applied for examination of the coupling device up to $2 \times 10^{6}$ cycles, Fig. 4 . An amplitude of the force signal was calculated using the following relationship: 
$\mathrm{F}_{\mathrm{hs} \text { res }}= \pm 0.6 \mathrm{D}$,

where: $D$ - force declared by the producer. According to the standard (Regulation No 55) its magnitude is defined by the following expression:

$D=\frac{m_{C} m_{T}}{m_{C}+m_{T}} \cdot g$,

where: $\mathrm{m}_{\mathrm{C}}$ - vehicle mass, $\mathrm{m}_{\mathrm{T}}$ - trailer mass; $\mathrm{g}$ - acceleration due to gravity. Parameters of the coupling device are detailed on its technical specification.

A frequency of the cyclic force is determined on the basis of working conditions of structural components taken into account. Here, it was equal to $10 \mathrm{~Hz}$. According to the standard (Regulation No 55) the maximum frequency should be lower than $35 \mathrm{~Hz}$. An angle of the force is determined by the relationship between a centre of the coupling ball and a horizontal line passing through the fixing point of the coupling device which is the highest of the nearest. If the line is above the ball centre, the test shall be conducted at an angle $+15^{\circ} \pm 1^{\circ}$ (Fig. 4), otherwise $-15^{\circ} \pm 1^{\circ}$. Deformation and cracks are the basis for recognizing the inherent quality of the product tested.

Among the most important features of the experimental procedure one can indicate a mounting of the equipment in the same position as it appears during exploitation. The coupling device was tested to check whether it could be mounted in the Sports Utility Vehicle (in this case Hyundai Tucson). Markers were used to capture displacement in 3D coordinate system, Fig. 4. They were stuck along the major axis of the coupling device.

The boat frame was examined using displacement control. Symmetrical signals were applied to load a beam. An induction sensor was used to measure a movement in the selected single direction. Markers for DIC analysis were located along major axes of the frame components tested. The basic coordinate system was attributed to the anti-vibration platform. The main aim of the experiment was to examine the frame resistance under fatigue conditions.

DIC system was also used to investigate vibration of 3.0 diesel engine of Porsche Cayenne (SUV) after exploitation. In this case markers were arranged on the engine cover and bumper of the car. The major engine axis was rotated under rotational velocity up to 2500 RPM. The aim of this experiment was to identify vibrations of the car engine with respect to exhaustion of the gummetal absorbers.

The PONTOS 5M was applied in all stages of the experimental procedure to capture variations of displacement as a function of time. It enabled to determine distribution of displacement vectors in $2 \mathrm{D}$ and $3 \mathrm{D}$ coordinate systems. The results were analysed in order to indicate a characteristic features of the objects examined.

\section{RESULTS}

Data showing variations of displacement for the structural components tested are presented in Figs. $4 \div 6$. Looking at the results a distribution of displacement vectors can be easily studied.

In the case of coupling device this data were represented by displacement in the $0 x$ direction, because such data are very important from engineering point of view. The results necessary for designing of this element can be easily deduced basing on DIC's data. They can be presented in the form of digital files including 3D displacement components versus time. On the basis of these data a location and deflection of major axis of the coupling device can be established. Such results also enable identification of the weak and strong zones under the cyclic loading. More importantly, a movement of elements in the mounting zone can be evaluated.

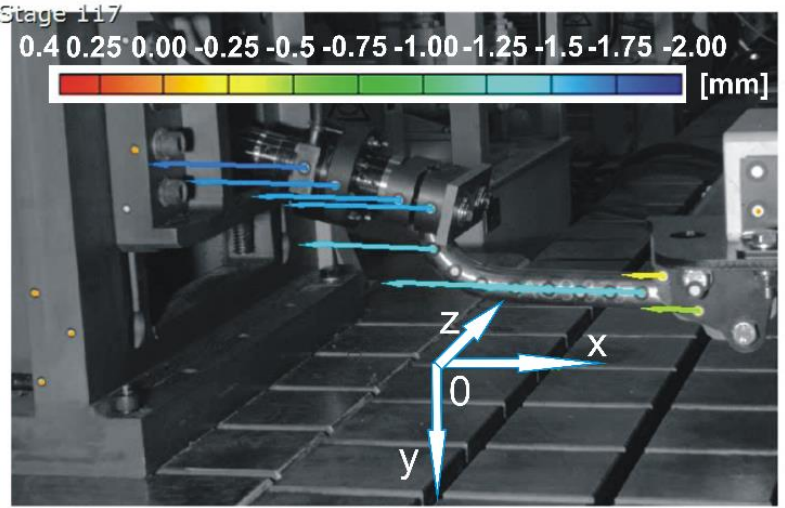

Fig. 4. Distribution of displacement in $0 x$ axis direction for mechanical coupling device examined under cyclic loading

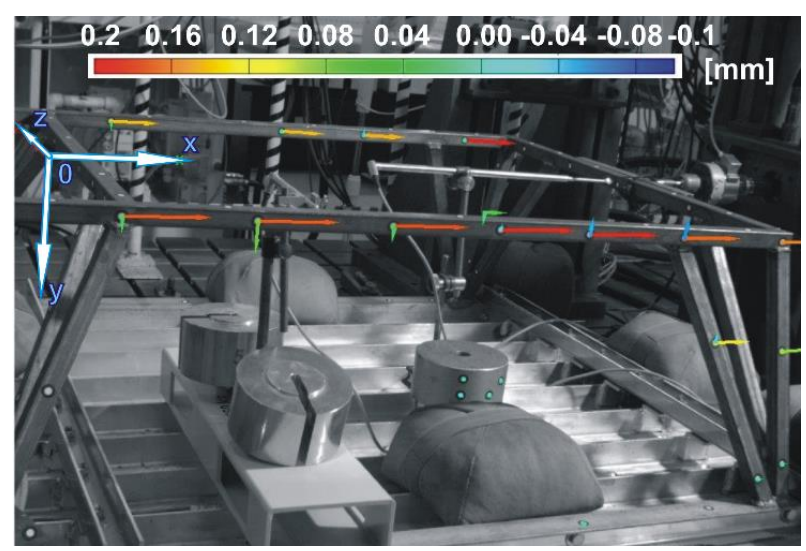

Fig. 5. Components of displacement in 3D coordinate system determined in fatigue test of the boat frame at $1 \times 10^{6}$ cycles

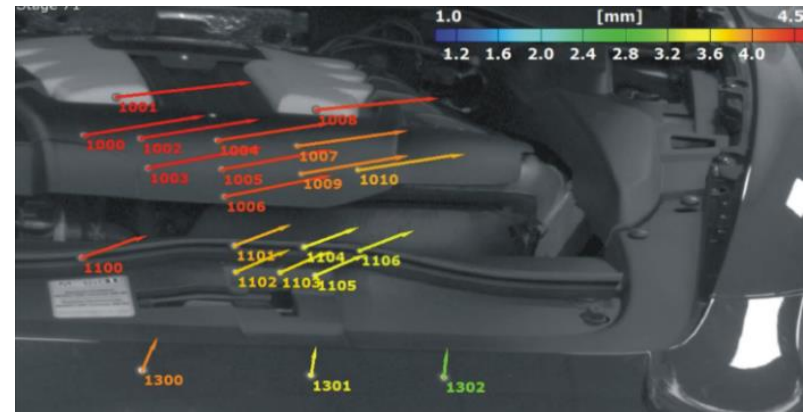

Fig. 6. Distribution of resultant displacement vector in 3D coordinate system for selected rotational velocity of the car engine of Porsche Cayenne

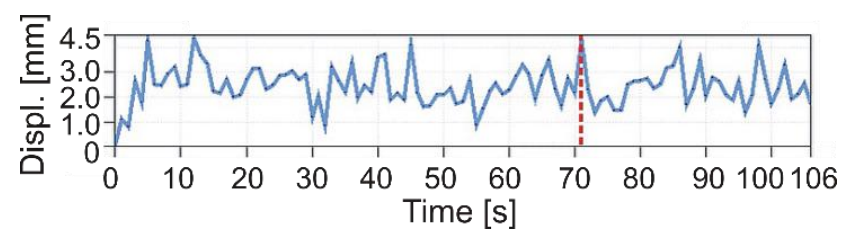

Fig. 7. Magnitudes of the displacement vector in 3D coordinate system for the 3.0 diesel car engine of Porsche Cayenne after exploitation (results representing point 1004 in Fig. 6) 
The results representing boat frame investigation are illustrated in the form of displacement vector components, Fig. 5. They enable to distinguish differences between movement of beams and bracket. Also a behaviour of the weld zones can be characterised (appeared in the lowest part of the structural component), Fig. 5. The weakest regions can be easily identified, since they are represented by a low stiffness or damage zones that correspond to the displacement increase.

Car engine was studied on the basis of variations of displacement resultant vector serving as the effective indicator of vibrations, Fig. 6 . In the analysis an orientation of the vectors was considered. The vectors were determined for different values of rotational velocity. The results showed a single direction of displacement vector. It was observed for the entire range of rotational velocity applied (up to 2500 RPM). In comparison to the typical behaviour of car engine the vectors length and direction well identify a difference in mechanical properties of the gummetal absorber. It is clearly illustrated in Fig. 7. The resultant vector achieved the maximum value equal to $4.5 \mathrm{~mm}$. On the basis of these data engineers are able to estimate exhaustion of the anti-vibration components.

\section{SUMMARY}

DIC method enables capturing the results in 2D and 3D coordinates systems for various types of loading (static or cyclic).

It can be used for determination of the full-field strain maps, stress-strain characteristics and such mechanical properties as: Young's modulus, yield point and ultimate tensile strength. The results can be elaborated in the form of maps representing distribution of: strain components, major and minor strain, and equivalent strain.

In the case of structural components their kinematic quantities, like a displacement, velocity and acceleration, can be determined as a function of time. Each of them can be represented by vectors, and variations of their magnitudes versus time. On the basis of DIC results a deflection together with detection of the strong and soft zones located on the structural components can be effectively identified.

\section{REFERENCES}

1. Baqersada J., Carra J., Lundstroma T., Niezrecki Ch., Avitabilea P., Slattery M., (2012), Dynamic characteristics of a wind turbine blade using 3D digital image correlation, Health Monitoring of Structural and Biological Systems 2012, edited by Tribikram Kundu, Proc. of SPIE, 8348.

2. Berger H., Klein M., Lambert F., Levadoux B., (2010), Optical Vibration Measurement and Frequency Response Analysis on Large Structures under Multiple Excitation Load Conditions, Proceedings of ISMA2010 including USD2010, 1693-1702.
3. Bornert M., Brémand F., Doumalin P., Dupré J.-C., Fazzini M., Grédiac M., Hild F., Mistou S., Molimard J., Orteu J.-J., Robert L., Surrel Y., Vacher P., Wattrisse B., (2009), Assessment of Digital Image Correlation Measurement Errors: Methodology and Results, Experimental Mechanics, 49, 353-370.

4. Brinkmann Ch., Haberland J., Böttinger S., Erne O., Sanow G., (2007), Optical 3D Measuring System for Investigating Tyre Deformations, Tractor Technology, 62(5), 326-327.

5. Chu T.C., Ranson W.F., Sutton M.A., Peters W.H., (1985), Applications of digital-image-correlation techniques to experimental mechanics, Experimental Mechanics, 232-244.

6. Creager C., Johnson K., Plant M., Moreland S., Skonieczny K., (2015), Push-pull locomotion for vehicle extrication, Journal of Terramechanics, 57, 71-80.

7. Gower M.R., Shaw R.M., (2006), Towards a planar cruciform specimen for biaxial characterization of polymer matrix composites, Applied Mechanics and Materials, 24-25, 115-120.

8. Kamaya M., Kawakubo M., (2011), A procedure for determining the true stress-strain curve over a large range of strains using digital image correlation and finite element analysis, Mechanics of Materials, 43, 243-253.

9. Long X., Fu S., Qi Z., Yang X., Yu Q., (2012), Digital image correlation using stochastic parallel-gradient-descent algorithm, Experimental Mechanics, DOI 10.1007/s11340-012-9667-4.

10. Szymczak T., Kowalewski Z.L., Brodecki A., (2016a), Determination of artificial defects in material under monotonic tension by the use of FEM and DIC methods, Materials Today: Proceedings, 3, 1171-1176.

11. Szymczak T., Kowalewski Z.L., Brodecki A., (2016b), Digital Image Correlation method for investigations of materials and engineering structures, Technical Suspervision (Dozór Techniczny), 4, 22-3 (in Polish).

12. Toussaint F., Tabourot I., Vacher P., (2008), Experimental study with a Digital Image Correlation (DIC) method and numerical simulation of an anisotropic elastic-plastic commercially pure titanium, Archives of Civil and Mechanical Engineering, VIII, 3, 131-143.

13. Regulation No 55 of the Economic Commission for Europe of the United Nations (UN/ECE) - Uniform provisions concerning the approval of mechanical coupling components of combinations of vehicles, 28.08.2010.

14. www.gom.com

Acknowledgement: This work has been supported by the National Science Centre through the Grant No 2014/15/B/ST8/04368 and the statutory project No. 6506/CBM/ITS founded by Ministry of Science and Higher Education. 